\title{
Anticorpos anti-hantavírus em escolares de Salvador, Bahia
}

\author{
Antibodies anti-hantavirus in schoolchildren \\ in Salvador, Bahia State, Brazil
}

\author{
Ana Veronica Mascarenhas-Batista, Elizabeth Salbé Travassos da Rosa, \\ Thomas G. Ksiazek, Amélia P.A. Travassos da Rosa, James W. Leduc, \\ Francisco Pinheiro e José Tavares-Neto
}

\begin{abstract}
Resumo As hantaviroses são doenças emergentes nas Américas e, em todo o mundo, os casos clínicos descritos foram infreqüentes entre crianças. O objetivo de investigar a freqüência de escolares portadores de anticorpos (IgG) anti-hantavírus justifica-se porque poucos estudos soroepidemiológicos pesquisaram a infecção por hantavírus no grupo pediátrico. Nos espécimes séricos de 379 escolares, de duas Escolas públicas da cidade do Salvador, Bahia, foram pesquisados os anticorpos anti-Hantaan (HTN) e anti-Sin Nombre (SN). A soropositividade de anticorpos anti-HTN foi de 13,2\% (50/379) e todos os escolares foram soronegativos para o vírus SN. A soropositividade anti-HTN aumentou proporcionalmente com a idade. Não houve associação entre a soropositividade anti-HTN e as características relacionadas à exposição a roedores urbanos. A soroprevalência de anticorpos anti-HTN nos escolares estudados foi elevada e reforçou a hipótese de circulação de hantavírus em Salvador. A não observação de portadores de anticorpos anti-SN indica, provavelmente, a circulação de outros sorotipos nesta região, mais relacionados antigenicamente ao sorotipo Hantaan.
\end{abstract}

Palavras-chaves: Hantavírus. Hantaan. Sin Nombre. Crianças.

\begin{abstract}
Hantavirosis are emerging diseases in the Americas. Although considered rare in children, among the five cases diagnosed in Brazil, one was in this age group. To know the serum-prevalence of hantavirosis in the pediatric group (schoolchildren) of low social economic level in Salvador, Bahia State, and to associate demographic, socio-economic and enviromental factors to the serologic results, a standard questionaire was applied and blood samples were colected from 379 students of two public schools. Sera were tested by Indirect Imunofluorescent Antibody (IFA) IgG for Hantaan Virus (HTN) and Imunoenzimatic test (ELISA) for Sin Nombre viruses. Ages varied from five to seventeen years with a mean age of 10.2 years. The proportion of sera positive to HTN virus was $13.2 \%$, and there were no positive antibodies to $S N$ virus. The frequency of positivity was higher in the older group, similar among sexes and racial groups, and there was no association with the exposure to urban rodents. The antibodies anti-HTN serum-prevalence in low social economic level school children is high and confirm the circulation of hantaviruses in Salvador-Bahia, Brazil; the nonobservation of antibodies anti-SN indicates that the species are other than Sin Nombre Virus.
\end{abstract}

Key-words: Hantavirus. Hantaan. Sin Nombre. Children.

Departamento de Medicina da Faculdade de Medicina da Universidade Federal da Bahia, Salvador, BA; Instituto Evandro Chagas, Belém, PA e Centro de Controle de Doenças (CDC), Atlanta.

Financiamento: CNPq e CAPES (PET-Medicina).

Endereço para correspondência: Dr. José Tavares-Neto, Faculdade de Medicina/Hospital Universitário Prof. Edgard Santos, Campus Canela, 40110-160 Salvador, BA.

Recebido para publicação em 25/9/97. 
As hantaviroses são infecções causadas por um grupo de vírus pertencentes ao gênero Hantavirus 26, família Bunyaviridae e transmitidas à espécie humana primariamente por roedores silvestres. Na atualidade, são conhecidos pelo menos 14 sorotipos e diversos outros estão sendo caracterizados. Levando em consideração que apenas $5 \%$ das espécies de roedores têm sido testada para a presença de hantavírus, esperase que outros membros do gênero sejam isolados em um futuro próximo. $\mathrm{O}$ isolamento em 1976 do sorotipo Hantaan, agente etiológico da febre hemorrágica da Coréia 14 , propiciou notável avanço no conhecimento das formas de transmissão e disseminação da febre hemorrágica com síndrome renal (FHSR). A identificação em 1993 do hantavírus Sin Nombre, no sudoeste dos Estados Unidos 1 , motivou várias investigações para detectar outros hantavírus e como resultado 16 soro/genotipos foram descritos, bem como descrições das características clínico-epidemiológicas das hantaviroses no continente americano10.

No Brasil, evidências sorológicas indicaram a infecção por hantavírus em roedores urbanos 11 e em diferentes populações humanas 45671922232425 , além de casos clínicos sugestivos de hantavirose nos Estados de Pernambuco22, São Paulo5, Mato Grosso22, Pará2 17 e Bahia 16 , especialmente entre pacientes com diagnóstico presuntivo de leptospirose 21 .

A menor soroprevalência de infecção por hantavírus em crianças suecas e chinesas foi atribuída a uma menor exposição a roedores urbanos e silvestres ${ }^{9}$. Considerando que na literatura há poucos estudos sobre a doença e, especialmente, a infecção em crianças, buscamos levantar a freqüência de portadores de anticorpos anti-hantavírus em escolares de dois bairros da cidade do Salvador, Estado da Bahia.

\section{MATERIAL E MÉTODOS}

Os escolares de duas escolas públicas, respectivamente dos bairros de Monte Serrat e Bonfim, da cidade do Salvador, BA, ambos localizados no Distrito de Itapagipe, foram incluídas no estudo seccional, desde que menores de 18 anos, estudassem em período diurno e tivessem o consentimento formal dos pais ou responsáveis legais. No período de 1 a 15 de dezembro de 1994, de cada escolar amostrado foi coletado $5 \mathrm{ml}$ de sangue; os espécimes séricos foram conservados a $-20^{\circ} \mathrm{C}$ até a realização dos exames sorológicos (janeiro de 1996).
Nos procedimentos sorológicos, foram usadas as seguintes técnicas: a) imunofluorescência indireta (IFI) usando células VERO infectadas pelo sorotipo Hantaan (protótipo), fixadas em acetona, e conjugado Fluoline G (globulina antiIgG humana marcada com isotiocianato de fluoresceína da $\left.B I O L A B{ }^{\circledR}\right)$; os soros a serem testados e os soros controles positivos ( $\lg G$ ) e negativos foram diluídos em placas de microtitulação de poliestireno; as amostras séricas consideradas como soropositivas apresentaram $1 \%$ ou mais de focos fluorescentes na titulação $1 / 3211$ e b) enzyme linked immunosorbent assay (ELISA) utilizando o antígeno recombinante (Lote $n^{\circ}$ SPR 293) do nucleocapsídeo do sorotipo Sin Nombre (Muerto Canyon Virus) e controle-negativo do antígeno (Lote no SPR 292) fornecidos e segundo a técnica descrita por Ksiazek et al10, bem como, os soros controles negativos (soros humanos previamente testados) e positivo (Lote 703109), segundo comunicação pessoal de Ksiazek TG. Nesta técnica, o conjugado (soro de cabra anti-lgG humana conjugado a peroxidase) foi da SIGMA ${ }^{\circledR}$ e o substrato ABTS de Kirkeergard \& Perry Laboratories ${ }^{\circledR}$ (2.2'azino-di-(3-ethil-benzthiazoline sulfonate), sendo a leitura realizada no espectrofotômetro LABSYSTEM Multiskan, Plus type 314 usando filtro de $405 \mathrm{~mm}$. Os valores espectrofotométricos considerados positivos tiveram densidade ótica corrigida maior que o cut-off de 0,2 - conforme orientação de Ksiazek (Ksiazek TG, comunicação pessoal, 1995).

Além dos dados demográficos (gênero, idade, grupo racial e local da residência) de cada escolar, foi utilizada a variável nível sócioeconômico (NSE) extraída do somatório dos escores das seguintes variáveis: a) anos de estudo do pai (com as seguintes faixas intervalares e respectivos escores: $0|-| 1=0,2 \mid$ $|4=1,5|-|8=2,9|-\mid 11=3, \geq 12=4 ; b)$ anos de estudo da mãe (idem); c) e d) ocupação do pai e da mãe, respectivamente, foram classificadas de acordo com o grau de escolaridade e complexidade de treinamento profissional (desempregado $=0$, primária nãoespecializada $=1$, primária especializada $=2$, secundária $=3$ e terciária $=4$ ); e) água encanada no domicílio (não $=0$ e $\operatorname{sim}=1$ ); f) rede de esgoto (não = 0 e $\operatorname{sim}=1$ ); g) freqüência semanal da coleta de lixo (não tem coleta $=0 ; 1$ a 2 vezes/semana $=1 ; 3$ a 5 vezes $=2 ; \geq 6=3) ; \mathrm{h}$ ) depósito de lixo próximo à residência (não $=1 \mathrm{e}$ $\operatorname{sim}=0$ ); i) rua alagada no período das chuvas 
$(\operatorname{sim}=0$ e não $=1) ; j)$ calçamento na rua onde mora (não $=0$ e sim $=1$ ); ) ratos no domicílio $(\operatorname{sim}=0$ e não $=1)$; I) vala de esgoto na rua $(\operatorname{sim}=0$ e não $=1)$ e $\mathrm{m})$ número de moradores por dormitório ( 0 a $2=2$; 3 a $4=1 ; 5+=0$ ). Outras variáveis também relacionadas ao contato com roedores urbanos (Rattus $s p$ ) foram investigadas: a) presença de ratos na rua onde reside; b) atividades recreativas próximas a depósito de lixo e c) contato com terra (quintal da residência e/ou na rua).

$\mathrm{Na}$ análise estatística, o resultado da sorologia, presença ou ausência de anticorpos anti-hantavírus, foi dicotomizado em positivo ou negativo, respectivamente. Os dados foram analisados pelo programa EPI INFO versão 6 , usando testes estatísticos paramétricos ou não, conforme o tipo da variável. O resultado foi considerado significativo quando a probabilidade (p) do erro tipo I $(\alpha)$ foi $\leq 0,05$.

\section{RESULTADOS}

Nas duas escolas estudavam 459 crianças, nos turnos matutino e vespertino, sendo 274 na Escola Pio XII (bairro Monte Serrat) e 185 na Escola Prof. Freire Filho (bairro Bonfim). De 345 escolares $(75,6 \%)$ as informações foram completas, sendo $212(77,4 \%)$ da Escola Pio XII e $133(71,9 \%)$ da Escola Prof. Freire Filho; de outros 34 escolares a amostra sangüínea e os dados demográficos foram também coletados, mas não completaram as informações do levantamento. As demais crianças $(n=80)$ foram excluídas, porque o responsável legal pelo escolar não compareceu no dia da coleta da amostra sangüínea.

A idade variou de 5 a 17 anos, com média de $10,2 \pm 2,7$ anos e mediana de 10 anos. $\mathrm{Na}$ Tabela 1, a média de idade dos escolares da Escola Professor Freire Filho foi 11,5 $\pm 2,2$ anos

Tabela 1 - Características demográficas dos escolares submetidos à pesquisa de anticorpos (IgG) anti-Hantaan de duas escolas da cidade do Salvador, Bahia.

\begin{tabular}{|c|c|c|c|c|c|c|}
\hline \multirow{2}{*}{$\begin{array}{l}\text { Características } \\
\text { demográficas }\end{array}$} & \multicolumn{2}{|c|}{ Escola Prof. Freire Filho } & \multicolumn{2}{|c|}{ Escola Pio XII } & \multicolumn{2}{|c|}{ Total } \\
\hline & $\mathrm{n}=147$ & $\%$ & $n=232$ & $\%$ & $\mathrm{n}=379 \mathrm{a}$ & $\%$ \\
\hline \multicolumn{7}{|l|}{ Gênero } \\
\hline masculino & 79 & 53,7 & 124 & 53,4 & 203 & 53,6 \\
\hline feminino & 68 & 46,3 & 108 & 46,6 & 176 & 46,4 \\
\hline \multicolumn{7}{|l|}{ Idade (anos) } \\
\hline $5|-| 6$ & 0 & 0 & 40 & 17,2 & 40 & 10,6 \\
\hline $7|-| 8$ & 10 & 6,8 & 54 & 23,3 & 64 & 16,9 \\
\hline $9|-| 10$ & 49 & 33,3 & 53 & 22,8 & 102 & 26,9 \\
\hline $11|-| 12$ & 38 & 25,9 & 57 & 24,6 & 95 & 25,1 \\
\hline $13|-| 14$ & 36 & 24,5 & 21 & 9,1 & 57 & 15,0 \\
\hline$>14$ & 14 & 9,5 & 7 & 3,0 & 21 & 5,5 \\
\hline \multicolumn{7}{|l|}{ Grupo racial } \\
\hline branco & 3 & 2,0 & 8 & 3,4 & 11 & 2,9 \\
\hline mulato & 112 & 76,2 & 190 & 81,9 & 302 & 79,7 \\
\hline negro & 32 & 21,8 & 34 & 14,7 & 66 & 17,4 \\
\hline \multicolumn{7}{|c|}{ Local de residênciaa } \\
\hline Itapagipe & 106 & 79,7 & 203 & 95,8 & 309 & 89,5 \\
\hline outros bairrosb $^{b}$ & 6 & 4,5 & 6 & 2,8 & 12 & 3,5 \\
\hline suburbana & 21 & 15,8 & 3 & 1,4 & 24 & 7,0 \\
\hline \multicolumn{7}{|c|}{ Nível sócio-econômicoa } \\
\hline escore $2|-| 8$ & 8 & 6,0 & 5 & 2,4 & 13 & 3,8 \\
\hline $9|-| 13$ & 55 & 41,4 & 67 & 31,6 & 122 & 35,4 \\
\hline $14|-| 18$ & 56 & 42,1 & 112 & 52,8 & 168 & 48,7 \\
\hline $19|-| 25$ & 14 & 10,5 & 28 & 13,2 & 42 & 12,1 \\
\hline
\end{tabular}

$\mathrm{a}=\mathrm{o}$ bairro da residência e nivel sócio-econômico definidos somente em 133 escolares da Escola Prof. Freire Filho e em 212 escolares da Escola Pio XII; b = outros bairros: San Martin, Campina de Pirajá, Liberdade, Pero Vaz, Engenho Velho de Brotas, Brotas, Pernambués, Sabueiro, Mata Escura e Pau da Lima. 
e dos escolares da Escola Pio XII foi 9,3 $\pm 2,7$ anos, sendo diferentes entre si (teste $t=8,17 ; p$ $<0,0000001)$. Não houve diferenças entre os escolares das duas escolas quanto ao gênero $\left(\chi^{2}=0 p>0,95\right)$ e grupo racial, branco versus não-branco (Yates: $\chi^{2}=0,2 ; p>0,63$ ). Também na Tabela 1, a maioria dos escolares da Escola Pio XII residia no Distrito de Itapagipe (95,8\%). A maioria dos escolares da Escola Professor Freire Filho também residia no Distrito de Itapagipe $(79,7 \%)$, entretanto, $21(15,8 \%)$ escolares dessa escola residiam na zona Suburbana, sendo a diferença altamente significativa $\left(\chi^{2}=22,5 ; p\right.$ $<0,000001$ ). A pontuação do nível sócioeconômico (NSE) variou de 2 a 25 pontos, com moda e mediana de 14. A Tabela 1 mostra a distribuição dessa variável entre os escolares das duas escolas. Nos escolares da Escola Pio XII, o NSE (variável dicotomizada segundo a mediana em dois grupos: $<14$ e $\geq 14$ ) foi significativamente mais elevado, do que o dos escolares da Escola Professor Freire Filho $\left(\chi^{2}=6,2 ; p<0,01\right)$.

Nenhuma criança apresentou anticorpos séricos contra o vírus Sin Nombre (SN). A presença de anticorpos IgG imunofluorescentes anti-Hantaan (HTN) foi observada em 13,2\% (50/379) dos espécimes séricos analisados. As prevalências de portadores de anticorpos antiHantaan entre os escolares das duas escolas foram semelhantes $\left(\chi^{2}=0,01 ; p>0,90\right)$, sendo de $13,4 \%$ (31/232) na Escola Pio XII e 12,9\% $(19 / 147)$ na Escola Professor Freire Filho.

A média de idade dos soropositivos foi de $10,7 \pm 2,9$ anos e a dos soronegativos de $10,1 \pm 2,7$ anos $(t=1,42 ; p>0,15)$. Distribuindo as idades em classes intervalares observou-se aumento das freqüências de anticorpos antihantavírus com a idade, exceto na faixa etária de 5 a 6 anos, como mostrado na Tabela 2, porém sem alcançar significância estatística $\left(\chi^{2}=0,12 ; p>0,71\right)$. A presença de anticorpos anti-hantavírus foi detectada em 11,9\% (21/176) dos escolares do gênero feminino e em $14,3 \%$ (29/203) dos escolares masculinos, sendo a diferença não significativa $\left(\chi^{2}=0,46 ; p>0,50\right)$. Anticorpos anti-hantavírus não foram observados em escolares brancos $(n=11)$, mas ocorreram em $9,1 \%(6 / 66)$ dos negros e $14,6 \%(44 / 302)$ dos mulatos. Comparando as freq(ências de soropositivos e soronegativos entre negros e mulatos a distribuição foi semelhante $\left(\chi^{2}=0,90\right.$; $\mathrm{p}>0,30)$; o mesmo ocorrendo quando se comparou escolares brancos versus os não- brancos $\left(\chi^{2}=0,74 ; p>0,38\right)$. Quanto ao local de residência, $13,3 \%$ dos escolares com anticorpos anti-hantavírus (41/309) residiam no Distrito de Itapagipe (Monte Serrat, Bonfim, Ribeira e Uruguai), enquanto $12,5 \%$ (3/24) dos soropositivos moravam na região Suburbana e 25,0\% (3/12) em outros bairros da cidade do Salvador. Porém, as diferenças nas freqüências de soropositivos, segundo o local da residência, não foram estatisticamente significativas, conforme assinalado na Tabela 2.

Também na Tabela 2, os escolares portadores ou não de anticorpos anti-Hantaan foram distribuídos conforme o nível sócio-econômico (NSE) em escala intervalar, porém, não se observou diferença estatisticamente significativa entre as quatro classes avaliadas. Quando o nível sócio-econômico foi dicotomizado em $<14$ e $\geq 14$, conforme o valor da mediana, as freqüências de soropositivos foram respectivamente $13,3 \%$ e $13,8 \%\left(\chi^{2}=0,02 ; p\right.$ $>0,80$ ). Não foi observada associação entre as características ambientais estudadas, relacionadas ao contato com roedores urbanos e a presença de anticorpos nos escolares. No entanto, conforme mostrado na Tabela 3, os portadores de anticorpos anti-Hantaan relataram mais freqüentemente presença de ratos na rua onde residiam $(p>0,06)$ e atividades recreativas próximas a depósito de lixo $(p>0,07)$, sem alcançar significância estatística.

\section{DISCUSSÃO}

A prevalência de $13,2 \%$ portadores de anticorpos imunofluorescentes anti-Hantaan entre os escolares estudados, da cidade do Salvador, reforça a circulação e a relevância da infecção por hantavírus em nosso meio. Embora escassos, os estudos de soroprevalência da infecção por hantavírus entre crianças de zonas endêmicas indicaram soropositividade consideravelmente mais baixa nessa faixa etária. Na Suécia, menos de $2,0 \%$ das crianças tinham anticorpos imunofluorescentes contra o hantavírus Puumala18, sendo na China de $8,5 \%$ a positividade para os sorotipos Hantaan e Seoul20. No Brasil, no único estudo sorológico realizado com a inclusão de crianças, internadas em hospital de doenças infecciosas, a freqüência de soropositivos anti-Hantaan foi de 16,2\%24.

No presente estudo, a possibilidade de alguns resultados falso-positivos não pode ser descartada. Todavia, a utilização do título de 1:32 para considerar um soro como positivo 
Tabela 2 - Freqüência de escolares portadores de anticorpos (lgG) anti-Hantaan, na cidade do Salvador, Bahia, distribuídos conforme as variáveis demográficas estudadas.

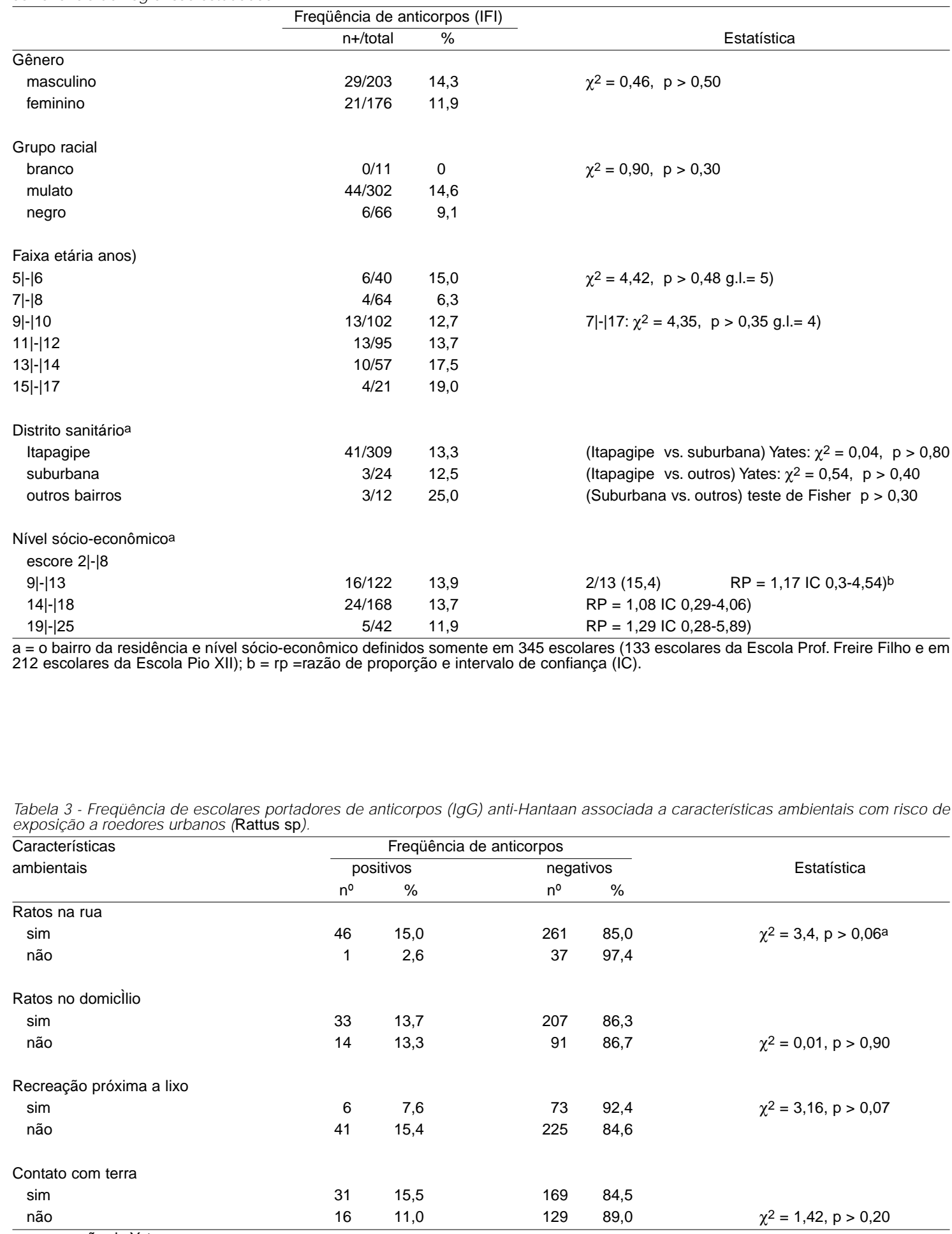

$\mathrm{a}=$ correção de Yates. 
minimizou a referida hipótese, uma vez que no teste de imunofluorescência indireta a menor diluição capaz de detectar anticorpos fluorescentes específicos é 1:1615. Embora haja tendência atual para utilizar-se a técnica de ELISA, provavelmente mais sensível e específica15 20, os estudos que compararam os resultados da sorologia anti-hantavírus, por IFI e ELISA numa mesma amostra, foram variáveis. Na Suécia, os inquéritos sorológicos encontraram dados concordantes entre esses dois testes sorológicos 18 . No Brasil, de 134 amostras de soro (15 amostras séricas foram excluídas do estudo publicado por Travassos da Rosa et al24) a concordância foi de $76,1 \%(102 / 134)$. Desse total, $9,0 \%(n=12)$ correspondiam a soros com anticorpos anti-HTN detectados pelas técnicas de ELISA e IFI e $67,1 \%(n=90)$ a soros negativos por ambas as técnicas. Neste estudo24, a discordância foi em 23,9\% $(n=32)$ dos resultados obtidos.

$\mathrm{Na}$ amostra analisada não se detectou anticorpos anti-Sin Nombre (SN) entre os escolares. Em indivíduos adultos da cidade do Salvador, a freqüência de portadores de anticorpos anti-SN foi de $0,2 \%(n=1)$ e de $0,4 \%$ $(n=2)$ com anticorpos anti-hantavírus Seoul (SEO) em 496 espécimes séricos analisados 23. Essas soropositividades baixas em adultos e a não observação em crianças (de anti-SN) sugerem a inexistência ou a muito baixa circulação do vírus SN, inclusive do SEO, em Salvador, bem como de outros hantavírus a eles antigenicamente mais relacionados. Estes resultados diferem dos encontrados em São Paulo, onde se observou soroprevalência de $4,1 \%(2 / 49)$ para o vírus SN4. Contudo, no estudo realizado em Juquitiba, São Paulo, a população estudada 4 era constituída por indivíduos comunicantes de três casos clínicos de síndrome pulmonar por hantavírus.

A menor prevalência de crianças portadoras de anticorpos anti-hantavírus é atribuída à menor exposição aos fatores de risco8. Todavia, a prevalência observada de escolares portadores de anticorpos anti-Hantaan (13,2\%) sugere maior exposição da população estudada aos roedores, comparativamente às crianças de outras áreas endêmicas da Suécia8 18 e da China20. No presente trabalho, não se observou associação significativa entre as características ambientais relacionadas aos contatos com roedores urbanos e a presença de anticorpos anti-hantavírus. Entretanto, vale ressaltar que o modelo (seccional) do presente estudo não é adequado à análise de fatores de risco.

Baseado nos relatos de que as freqüências de soropositivos aumentaram com a idade 1820 pode-se inferir, inclusive com base na prevalência encontrada entre os escolares estudados, que a prevalência nos indivíduos adultos, moradores da cidade do Salvador, seja mais elevada. Esse resultado foi mostrado em estudo anterior $24 \mathrm{e}$, mais recentemente, em doadores de sangue e garis de Salvador com soroprevalência de anticorpos imunofluorescentes anti-Hantaan de $27,2 \%(135 / 496)^{23}$. A freqüência observada de soropositividade de $15,0 \%$ na faixa etária de 5 a 6 anos chama a atenção, embora não estatisticamente diferente das demais faixas, até porque não foi observada em outros estudos. Apesar de não se dispor de explicação para esse dado, deve-se lembrar que a infecção congênita por hantavírus foi relatada na Coréia 12 .

A distribuição das freqüências de soropositivos anti-Hantaan entre os gêneros foi semelhante. Esse dado está concordante com o estudo realizado na China20, mas difere dos relatos observados na Suécia 18 , onde a soroprevalência foi maior no genêro masculino. No Estado da Bahia, Travassos da Rosa et al24 detectaram predominância da soroprevalência de anticorpos anti-Hantaan no gênero masculino. As diferenças relatadas podem ser atribuídas a maior exposição dos indivíduos do gênero masculino ao hantavírus 13 .

Não houve maior freqüência de escolares portadores de anticorpos anti-Hantaan entre os indivíduos de grupos raciais não-brancos. No Brasil, há evidente dualismo social entre os brasileiros-brancos e brasileiros-negros e mulatos, pois estes dois últimos grupos populacionais apresentam piores indicadores sociais. Todavia, a população estudada foi homogênea quanto aos indicadores sócio-econômicos e espelha, de modo adequado, os extratos sociais da cidade do Salvador sem acesso aos bens econômicos e de consumo. Também a população estudada foi representativa quanto aos indicadores sociais, quando se comparou esses indicadores associados ao risco de leptospirose em moradores dos distritos da cidade do Salvador (JCP Dias: comunicação pessoal, 1997). Por isto mesmo, outros estudos incluindo escolares mais diferenciados sócio-economicamente serão necessários, devido ao menor risco de exposição direta ou indireta aos roedores domésticos e peri-domiciliares. 
Em conclusão, a soroprevalência elevada $(13,2 \%)$ de escolares portadores de anticorpos imunofluorescentes anti-Hantaan reforça a necessidade de estudos clínicos, sorológicos e virológicos no Brasil. Este trabalho, por exemplo, poderia ser mais elucidativo se houvese realizado a pesquisa de anticorpos contra outros hantavírus, como o Seoul e o Puumala, já detectados no Brasil6 7, bem como o hantavírus Rio-Mamoré detectado em outros países da América do Sul3. No entanto, o custo operacional do estudo seria bem maior e, sem avaliação prévia, seria difícil seu planejamento. Os resultados do presente estudo e anteriores 2324 fornecem bases para futura investigação, evidenciando a relevância de estudos sorológicos e/ou virológicos com o protótipo Hantaan e outros hantavírus antigenicamente relacionados, como o Seoul (Girard Point) já isolado em ratos domésticos em Belém-Pará11. Até o momento, o vírus Sin Nombre ou outros vírus a ele relacionados (Black Creek Canal e Bayou) parecem não ter circulação em Salvador-Bahia.

\section{REFERÊNCIAS BIBLIOGRÁFICAS}

1. Centers for Disease Control. Hantavirus Pulmonary Syndrome - United States, 1993. Morbity Mortality Weekly Report 43:45-48, 1994.

2. Crescente JAB, Medeiros R, Cheng L, Brandão FF, De Cristo RNT, Lopes ML, Travassos da Rosa ES. Indicativo de infecção aguda simultânea por leptospira e hantavírus. In: Resumos do IX Congresso Brasileiro de Infectologia, Recife p.162, 1996.

3. Hjelle B, Torrez-Martinez N, Koster FT. Hantavirus pulmonary syndrome-related virus from Bolivia. The Lancet 347:57, 1996.

4. Iversson LB, Branquinho MS, Rosa MDB. Inquérito sorológico para pesquisa de infecção por Hantavírus em Juquitiba, Estado de São Paulo. In: Resumos do XXXI Congresso da Sociedade Brasileira de Medicina Tropical, São Paulo p.183, 1995a.

5. Iversson LB, Rosa MDB, Travassos da Rosa ES, Zaparoli MA, Pereira LE, Peters CJ. Investigação de comunicantes de casos de doença humana causada por Hantavírus em Juquitiba, Estado de São Paulo. In: Resumos do XXXI Congresso da Sociedade Brasileira de Medicina Tropical, São Paulo p.183, 1995b.

6. Iversson LB, Sazaki MGM, Rosa MDB, Leduc JW. Prevalência de infecção por Hantavírus em portuários de Paranaguá, Estado do Paraná. In: Resumos do
XXXI Congresso da Sociedade Brasileira de Medicina Tropical, São Paulo p.184, 1995c.

7. Iversson LB, Travassos da Rosa APA, Rosa MDB, Lomar AV, Sasaki MGM, Leduc JM. Infecção humana por Hantavírus no sul e sudeste do Brasil. Revista da Associação Médica Brasileira 40:85-92, 1994.

8. Khan AS, Khabbaz RF, Armstrong LR, Holman RC, Bauer SP, Graber J, Strine T, Miller G, Reef S, Tappero J, Rollin PE, Nichol ST, Zazi SR, Bryan RT, Chapman LE, Peters CJ, Ksiazek TG. Hantavirus pulmonary syndrome: the first 100 US cases. The Journal of Infectious Diseases 173:1297-1303, 1996.

9. Khan AS, Ksiazek TG, Zaki SR, Nichol ST, Rollin PE, Peters CJ, Khabbaz RF, Cheek JE, Shireley LA, McDonough LS, Welty TK, Kuklinski D. Fatal hantavirus pulmonary syndrome in an adolescent. Pediatrics 95:276-280, 1995.

10. Ksiazek TG, Peters CJ, Rollin PE, Zaki SR, Nichol ST, Spiropoulou C, Morzunov MS, Feldmann H, Sanchez A, Khan AS, Mahy BWJ, Wachsmuth K, Butler JC. Identification of a new north american hantavirus that causes acute pulmonary insuficiency. American Journal of Tropical Medicine and Hygiene 52:117123, 1995.

11. Leduc JW, Smith GA, Pinheiro FP, Vasconcelos PFC, Travassos da Rosa ES, Maiztegui JI. Isolation of a Hantaan-related virus from Brazilian rats and serologic evidence of its widspread distribution in South America. American Journal of Tropical Medicine and Hygiene 34:810-815, 1985.

12. Lee HW. Hemorrhagic fever with renal syndrome in Korea. Reviews of Infectious Diseases 11 (supl 4):S864-S876, 1989a.

13. Lee HW. Epidemiology. In: Lee HW, Dalrymple JM (eds) Manual of hemorrhagic fever with renal syndrome. World Health Organization/ Colaborating Center for Virus Reference and Research/ Institute for Viral Diseases, Korea University, Korea p. 41-48, $1989 b$

14. Lee HW, Lee PW, Johnson KM. Isolation of the etiologic agent of Korean hemorrhagic fever. The Journal of Infectious Diseases 157:298-308, 1978.

15. Lee PW, Meegan JM, Tkachenko EA, Kitamura T, Tsai TF, Dalrymple JM Serologic techniques for detection of Hantaan virus infection, related antigens and antibodies In: Lee HW, Darymple JM (eds) Manual of hemorrhagic fever with renal syndrome World Health Organization/ Colaborating Center for Virus Reference and Research/ Institute for Viral Diseases, Korea Universiry, Korea p. 75-101, 1989. 
16. Mascarenhas-Batista AV. Soro-epidemiologia de hantavírus em escolares de Salvador-Bahia. Tese de Mestrado, Universidade Federal da Bahia, Salvador, BA, 1997.

17. Medeiros R, Crescente JAB, Cheng L, Brandão FF, De Cristo RNT, Lopes ML, Hinrichsen SL, Clement J. Doença por hantavírus em pacientes com suspeita clínica de leptospirose em Belém-Pará. In: Resumos do IX Congresso Brasileiro de Infectologia, Recife, $\mathrm{p}$. 162, 1996.

18. Niklasson B, Hornfeld B, Mullaart M, Settergren B, Tkachenko E, Myasnkov YA, Ryltceva EV, Leschinskaya E, Malkin A, Dzagurova T. An epidemiologic study of hemorrhagic fever with renal syndrome in Bashkirtostan (Russia) and Sweden. American Journal of Tropical Medicine and Hygiene 48:670-675, 1993

19. Romano-Lieber NS, Iversson LB, Fonseca LB, Fonseca BAL, Travassos da Rosa ES. Infecção humana por hantavírus em área da estação ecológica de Jureia-Itatins, Vale do Ribeira, SP. In Resumos do XXXI Congresso da Sociedade Brasileira de Medicina Tropical, São Paulo, p.184, 1995.

20. Ruo SL, Li YL, Tong Z, Ma QR, Liu ZL, Tang YW, Ye $\mathrm{KL}, \mathrm{Xu} Z \mathrm{ZY}, \mathrm{McC}$ ormick JB, Fisher-Hoch SP. Retrospective and prospective studies of hemorrhagic fever with renal syndrome in rural China. The Journal of Infectious Diseases 170:527-534, 1994.

21. Santos VM. Leptospirose e síndrome pulmonar por Hantavírus. Revista da Associação Médica Brasileira 40:225, 1994.
22. Simões ML, Teixeira MG, Araújo FA. Hantavírus. Informe Epidemiológico do SUS/Centro Nacional de Epidemiologia (CENEPI), Fundação Nacional de Saúde, Ministério da Saúde. Brasília, 3/4:37-48, 1994.

23. Torres-Morales AE, Tavares-Neto J, Travassos da Rosa E, Travassos da Rosa A. Seroprevalência de anticuerpos anti-hantavírus en Salvador - Bahia, Brasil. In: Resumos do V Congresso Latino-americano de Medicina Tropical, Havana, Cuba p.135, 1997.

24. Travassos da Rosa ES, Vasconcelos PFC, TavaresNeto J, Travassos da Rosa JFS, Rodrigues SG, Goes AC, Travassos da Rosa APA. Prevalence of antibodies to hantaviruses in Salvador, Bahia, Brazil. In: Resumos do XXXI Congresso da Sociedade Brasileira de Medicina Tropical, São Paulo p.185, 1995.

25. Vasconcelos PFC, Travassos da Rosa ES, Travassos da Rosa APA, Travassos da Rosa JFS. Evidence of circulating hantaviruses in Brazilian Amazonia through high prevalence of antibodies in residents of Manaus, Brazil. Ciência e Cultura 44:162-163, 1992.

26. Xiao S-Y, Leduc JW, Chu YK, Schmaljohn CS. Phylogenetic analyses of virus isolates in the Genus Hantavirus, Family Bunyaviridae. Virology 198: 205217, 1994. 